\title{
One-dimensional metal string complexes
}

\author{
Shie-Ming Peng, ${ }^{\mathrm{a}, \mathrm{b}, *}$, Chih-Chieh Wang ${ }^{\mathrm{a}}$, Yih-Lih Jang ${ }^{\mathrm{a}}$, Yu-Hua Chen ${ }^{\mathrm{a}}$, \\ Feng-Yin Li ${ }^{\mathrm{a}}$, Chung-Yuan Mou ${ }^{\mathrm{a}}$, Man-Kit Leung ${ }^{\mathrm{a}}$ \\ ${ }^{a}$ Department of Chemistry, National Taiwan University, 1 Sec, 4 Roosevelt Road, Taipei 106, Taiwan \\ binstitute of Chemistry, Academia Sinica, Taipei, Taiwan
}

\begin{abstract}
The metal string complexes with different metal ions and various lengths have been successfully synthesized and structurally characterized. The crystal and molecular structure of nonanickel complex $\left[\mathrm{Ni}_{9}\left(\mu_{9}-(\text { peptea })_{4} \mathrm{Cl}_{2}\right]\right.$ which is the longest metal string at this moment will be reported. Crystal data for $\left[\mathrm{Ni}_{9}\left(\mu_{9} \text {-(peptea }\right)_{4} \mathrm{Cl}_{2}\right]\left(\mathrm{C}_{2} \mathrm{H}_{4} \mathrm{Cl}_{2}\right)_{10}$ : Space

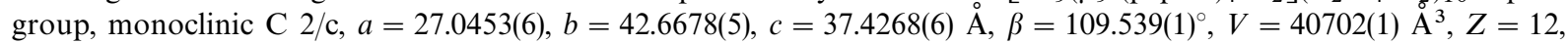
$\mathrm{R}_{\mathrm{F}}=12 \%$ for the observed reflections $(I>2 \sigma(I))$. The band structure calculation of infinite one-dimensional metal chains of $\mathrm{Ni}^{\mathrm{II}}$ and $\mathrm{Cr}^{\mathrm{II}}$ based on the structure of nonanickel complex will be presented. Finally, the metal string complexes $\left[\mathrm{M}_{n}^{\mathrm{II}} \mathrm{L}_{4} \mathrm{X}_{2}\right]$ will be chemisorbed on the Ag or Au surface and the potential application of these complexes as a molecular metal wire will be demonstrated. (C) 2000 Elsevier Science B.V. All rights reserved.
\end{abstract}

Keywords: Metal-metal multiple bonds; Antiferromagnetic interaction; Metal string complexes

The metal string complexes are highly interesting in the fundamental study of metal-metal interaction [1-13] and in their potential application as molecular metal wires. In order to build up a complete bonding scheme of metal-metal multiple bonds for polynuclear metal string complexes, a series of ligands, namely oligo- $\alpha$-pyridylamine ligands, were designed and their polynuclear metal string complexes were synthesized. The oligo- $\alpha-$ pyridylamino ligands that have been synthesized successfully were described as follows:<smiles>Cc1cccc(C(C)Nc2ccccn2)n1</smiles>

$$
\begin{array}{ll}
n=0 & \mathrm{Hdpa}=\text { dipyridylamine }\left(\mathrm{N}_{3}\right) \\
n=1 & \mathrm{H}_{2} \text { tpda = tripyridyldiamine }\left(\mathrm{N}_{5}\right) \\
n=2 & \mathrm{H}_{3} \text { teptra = tetrapyridyltriamine }\left(\mathrm{N}_{7}\right) \\
n=3 & \mathrm{H}_{4} \text { peptea = pentapyridyltetramine }\left(\mathrm{N}_{9}\right) \\
n=4 & \mathrm{H}_{5} \text { heppea = hexapyridylpentamine }\left(\mathrm{N}_{11}\right) \\
n=5 & \mathrm{H}_{6} \text { hpphea = heptapyridylhexamine }\left(\mathrm{N}_{13}\right)
\end{array}
$$

* Corresponding author. Tel.: + 886-2-23635357; fax: 886-223636359.

E-mail address: smpeng@mail.ch.ntu.edu.tw (S.-M. Peng)
The metal string complexes shown below are those that have been synthesized successfully.

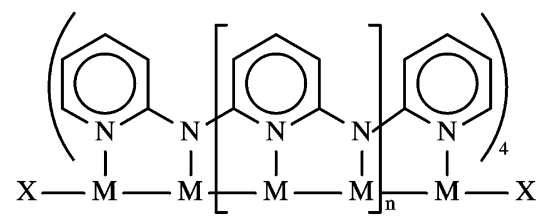

\begin{tabular}{|c|c|}
\hline$n$ & $\mathrm{M}$ \\
\hline 0 & $\mathrm{Cr}^{\mathrm{II}}, \mathrm{Ru}^{\mathrm{II}}, \mathrm{Co}^{\mathrm{II}}, \mathrm{Rh}^{\mathrm{II}}, \mathrm{Ni}^{\mathrm{II}}, \mathrm{Cu}^{\mathrm{II}}$ \\
\hline 1 & $\mathrm{Cr}^{\mathrm{II}}, \mathrm{Co}^{\mathrm{II}}, \mathrm{Ni}^{\mathrm{II}}$, \\
\hline 2 & $\mathrm{Cr}^{\mathrm{II}}, \mathrm{Ni}^{\mathrm{II}}$ \\
\hline 3 & $\mathrm{Cr}^{\mathrm{II}}, \mathrm{Ni}^{\mathrm{II}}$ \\
\hline
\end{tabular}

The number of metal ions successfully synthesized in these complexes is up to nine. The crystal structures of the metal string complexes from trinuclear to nonanuclear metal chains are essentially similar. The metal chains are co-linear with all the angles of $\angle \mathrm{M}-\mathrm{M}-\mathrm{M}$ being $\sim 180^{\circ}$ and the linear metal chain is wrapped by four all-syn type of deprotonated oligo- $\alpha$-pyridylamido ligands. The crystal structure of $\left[\mathrm{Ni}_{9}^{\mathrm{II}}\left(\mu_{9} \text {-peptea }\right)_{4} \mathrm{Cl}_{2}\right]$ 


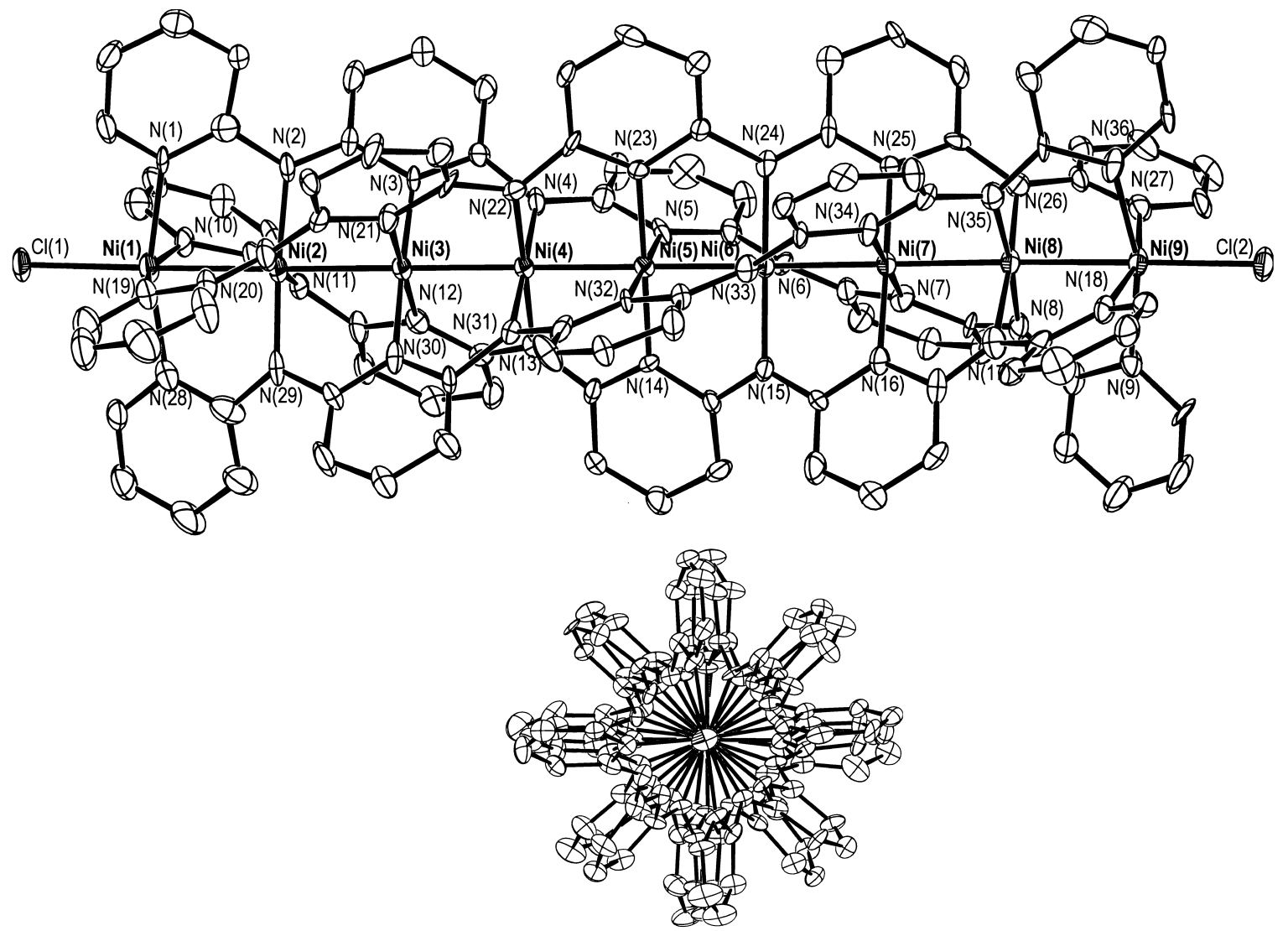

Fig. 1. (a) Crystal structure of $\left[\mathrm{Ni}_{9}\left(\mu_{9} \text {-peptea }\right)_{4} \mathrm{Cl}_{2}\right]$. (b) Top view along the $\mathrm{Ni}$ axis.
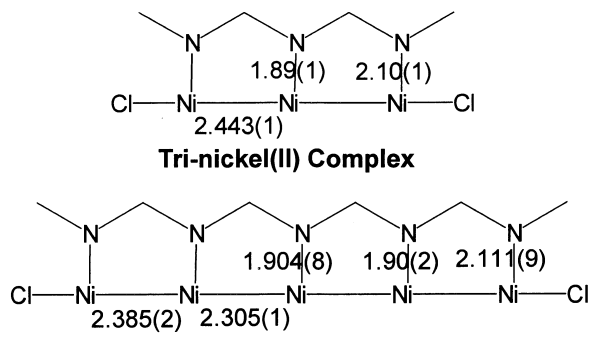

Penta-nickel(II) Complex
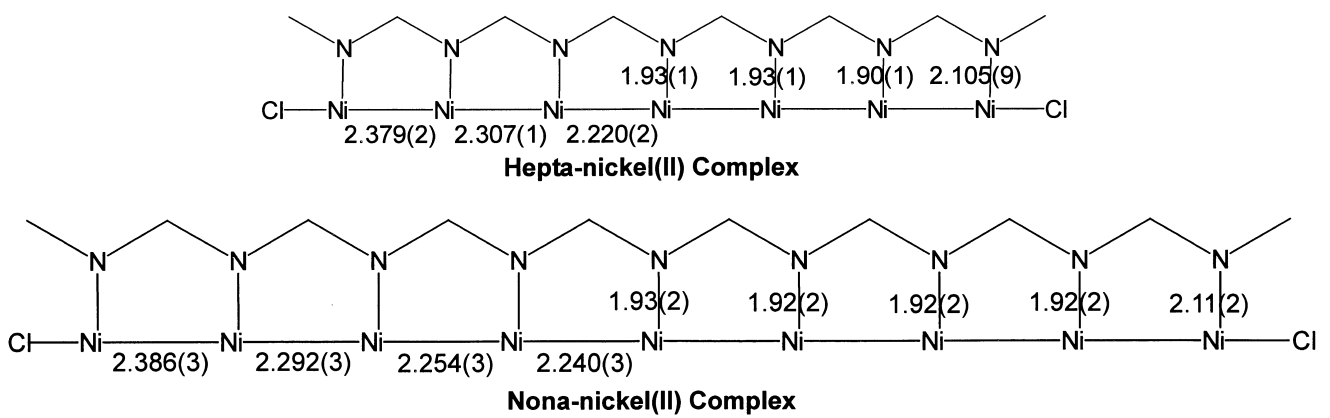

Fig. 2. Comparisons of Ni-Ni and Ni-N distances among tri-, penta-, hepta- and nonanickel(II) complexes. 


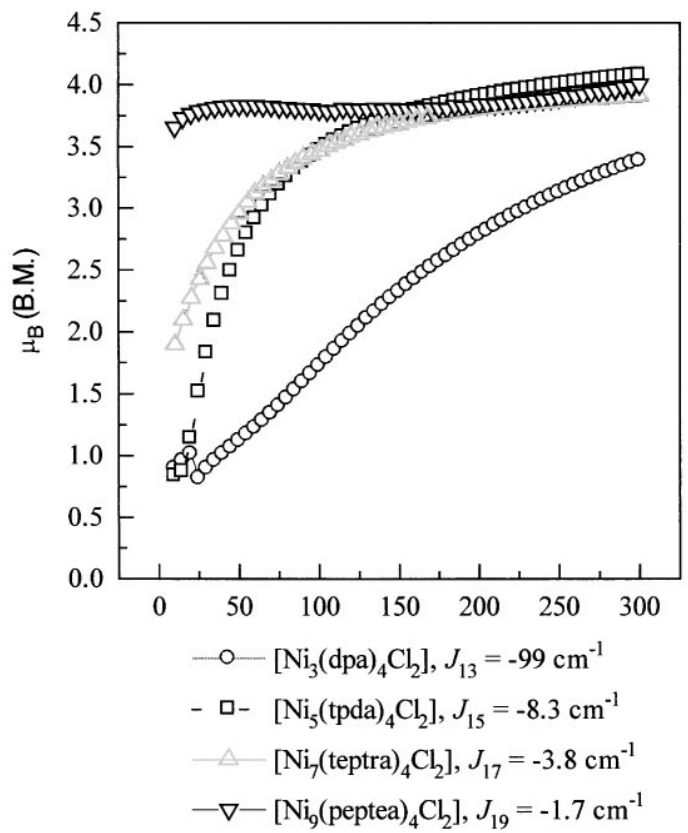

Fig. 3. Magnetic susceptibility measurements for tri-, penta-, hepta-, and nonanickel(II) complexes. The temperature-dependent magnetic susceptibility was measured on the SQUID system with a 10000 Gauss external magnetic field. Molar magnetic susceptibility was recorded every $5 \mathrm{~K}$ in the range of 5-300 K.

complex shown in Fig. 1(a) can clearly display the unique geometric conformation of these metal string complexes. The steric crowding of the $\beta$-carbon hydrogen atoms on the pyridyl rings forces the ligand to bind with the metal ion helically. Each oligo- $\alpha$-pyridylamido ligand is nonplanar, with an average dihedral angle among the planes of these pyridine rings of approximately $45^{\circ}$. An end view of the molecule looking down the $\mathrm{Ni}_{9}$ axis as shown in Fig. 1(b) gives a better view of the helical structure. Our effort to synthesize and characterize the metal string complexes has accumulated much systematic information on the bonding characterization beyond dinuclear metal systems. The comparisons of $\mathrm{Ni}-\mathrm{Ni}$ and $\mathrm{Ni}-\mathrm{N}$ distances among tri-nickel(II) to nonanickel(II) string complexes are shown in Fig. 2. Obviously, the terminal $\mathrm{Ni}-\mathrm{Ni}$ distances are longer than the inner Ni-Ni distances. The magnetic measurements of nickel metal string complexes shown in Fig. 3 reveal an antiferromagnetic interaction between two terminal high-spin nickel ions in the tri-, penta-, hepta-, and nonanickel(II) complexes while the inner nickel ions are diamagnetic. The coupling constant $(J)$ is roughly proportional to $r^{-3}$, where $r$ is the distance between two terminal nickel ions. These results are in accordance with the prediction by structural analysis with $\sim 2.10 \AA$ on terminal $\mathrm{Ni}-\mathrm{N}$ distances and $\sim 1.90 \AA$ on inner $\mathrm{Ni}-\mathrm{N}$ ones [10-12] and the XANES

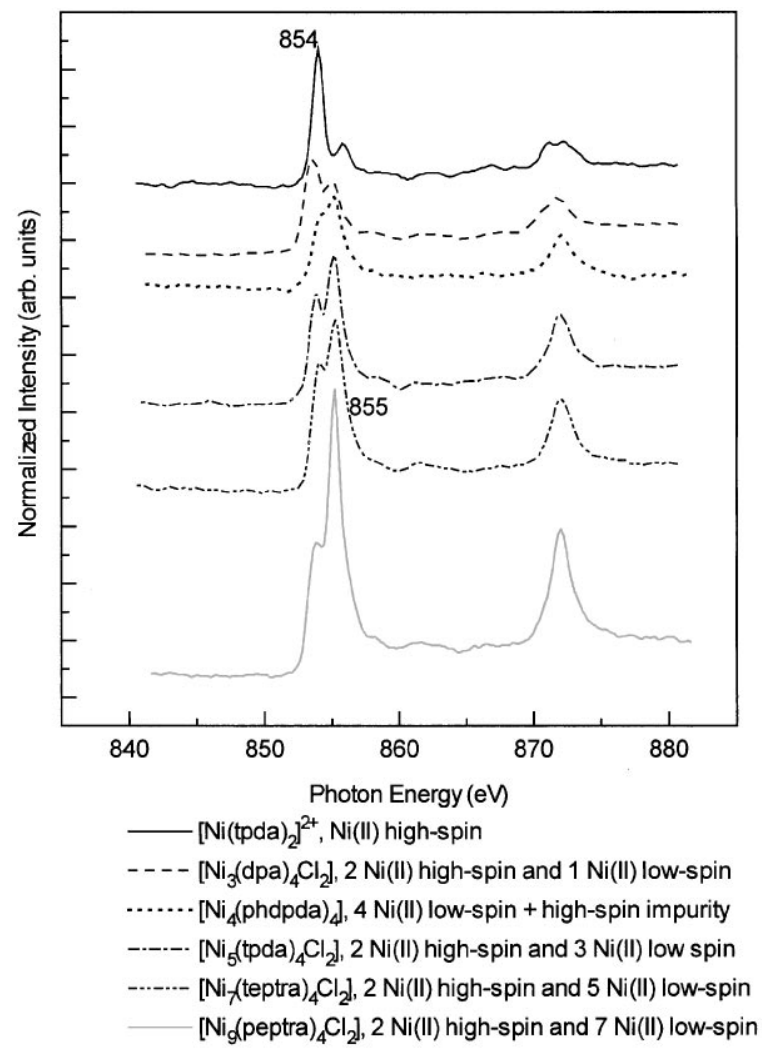

Fig. 4. XANES spectrum from trinickel(II) to nonanickel(II) complexes.

measurement in Fig. 4. Two unpaired electrons that delocalize among the tri-, pentachromium(II) centers with $\mu=3.6,4.0$, respectively, are found in the tri-, pentachromium(II) string complexes, which possess multinuclear metal-metal multiple bonds. This result is in accordance with the prediction by structural analysis and qualitative MO calculation. The electronic band structure of the molecular polynuclear metal complex indicates that the infinite linear $\mathrm{Ni}$ (II) complex is a semimetal with a slightly filled conduction band and the infinite linear $\mathrm{Cr}(\mathrm{II})$ complex can probably serve as a conducting wire.

The metal complexes $\left[\mathrm{M}_{3}^{\mathrm{II}}\left(\mu_{3}-\mathrm{dpa}\right)_{4}(\mathrm{NCS})_{2}\right]$ and $\left[\mathrm{M}_{5}^{\mathrm{II}}\right.$ $\left.\left(\mu_{5} \text {-tpda }\right)_{4}(\mathrm{NCS})_{2}\right]$ bind to the $\mathrm{Ag}$ or Au $\left[\begin{array}{lll}1 & 1 & 1\end{array}\right]$ surface to form a monolayer. The surface reflection IR spectrum shows that one of the thiocyanates is S-bonded to the $\mathrm{Ag}$ or $\mathrm{Au}$ atom $\left(v_{\mathrm{CN}}=2126 \mathrm{~cm}^{-1}\right)$. The sulfur atom of the other thiocyanate remains uncoordinated $\left(v_{\mathrm{CN}}=2063 \mathrm{~cm}^{-1}\right)$. The potential application of these complexes as a molecular metal wire will be demonstrated. Further work will be directed towards studying the structure and conductivity of those S-bonded metalchain complexes on the Ag and Au surfaces. 


\section{References}

[1] L.P. Wu, P. Field, T. Morrisey, C. Murphy, P. Nagle, B. Hathaway, C. Simmons, P. Thornton, J. Chem. Soc. Dalton Trans. (1990) 3835.

[2] G.J. Pyrka, M. El-Mekki, A.A. Pinkerton, J. Chem. Soc. Chem. Commun. (1991) 84.

[3] M.H. Yang, T.W. Lin, C.C. Chou, H.C. Lee, H.C. Chang, G.H. Lee, M.K. Leung, S.M. Peng, Chem. Commun. (1997) 2279.

[4] F.A. Cotton, L.M. Daniels, C.A. Murillo, I. Pascual, J. Am. Chem. Soc. 119 (1997) 10223.

[5] F.A. Cotton, L.M. Daniels, C.A. Murillo, X. Wang, Chem. Commun. (1998) 39.

[6] E.C. Yang, M.C. Cheng, M.S. Tsai, S.M. Peng, J. Chem. Soc., Chem. Commun. (1994) 2377.
[7] F.A. Cotton, L.M. Daniels, G.T. Jordan, IV, Chem. Commun., (1997) 421.

[8] F.A. Cotton, L.M. Daniels, G.T. Jordan, C.A. Murillo, J. Am. Chem. Soc. 119 (1997) 10377.

[9] S. Aduldecha, B. Hathaway, J. Chem. Soc., Dalton Trans. (1991) 993.

[10] J.T. Sheu, C.C. Liu, I. Chao, C.C. Wang, S.M. Peng, Chem. Commun. (1996) 315.

[11] S.J. Shieh, C.C. Chou, C.C. Wang, G.H. Lee, S.M. Peng, Angew. Chem. Int. Ed. Engl. 36 (1997) 56.

[12] C.C. Wang, W.C. Lo, C.C. Chou, G.H. Lee, J.M. Chen, S.M. Peng, Inorg. Chem. 37 (1998) 4059.

[13] S.Y. Lai, Z.W. Lin, Y.H. Chen, C.C. Wang, G.H. Lee, M.H. Yang, M.-K. Leung, S.M. Peng, J. Am Chem. Soc. 121 (1999) 250. 